\title{
BMJ open Screening for HIV among tuberculosis patients: a cross-sectional study in Sindh, Pakistan
}

\author{
Jamshed Hasnain, ${ }^{1}$ Ghulam Nabi Memon, ${ }^{1}$ Ashraf Memon, ${ }^{2}$ Abid Ali Channa, ${ }^{1}$ \\ Jacob Creswell, ${ }^{3}$ Sharaf Ali Shah ${ }^{1}$
}

To cite: Hasnain J,

Memon GN, Memon A, et al. Screening for HIV among tuberculosis patients: a cross-sectional study in Sindh, Pakistan. BMJ Open 2012:2:e001677.

doi:10.1136/bmjopen-2012001677

- Prepublication history for this paper are available online. To view these files please visit the journal online (http://dx.doi.org/10.1136/ bmjopen-2012-001677).

Received 15 June 2012 Accepted 30 August 2012

This final article is available for use under the terms of the Creative Commons Attribution Non-Commercial 2.0 Licence; see http://bmjopen.bmj.com

${ }^{1}$ Bridge Consultants Foundation,Karachi,Pakistan ${ }^{2}$ Sindh AIDS Control Program Referral Laboratory,Karachi, Pakistan

${ }^{3}$ Stop TB Partnership, World Health Organization, Geneva, Switzerland

Correspondence to Dr Jamshed Hasnain; drjhasnain@gmail.com

\section{ABSTRACT}

Objective: To describe feasibility and results of systematic screening of tuberculosis (TB) patients for HIV.

Design: Cross-sectional study.

Setting: Six selected sentinel sites (public DOTS clinics) in the province of Sindh, Pakistan.

Participants: All TB patients aged 16-60 years registered for treatment from April 2008 to March 2012.

Measurement: Demographic information of registered TB patients, screening for HIV through rapid testing and confirmation by referral lab of Sindh AIDS Control Program, according to national guidelines.

Results: Of a total of 18461 registered TB patients, 12882 fulfilled the inclusion criteria and were given education and counselling. Of those counselled 12552 $(97.4 \%)$ were screened for HIV using a rapid test. Men made up $48 \%$ of the sample and $76.5 \%$ of patients had pulmonary TB. Of the total patients tested, $42(0.34 \%)$ were HIV-positive after confirmatory testing at the Sindh AIDS Control Program Laboratory. Prevalence of HIV among male patients was $0.67 \%$ whereas prevalence among female patients was $0.03 \%$ ( $p$ value $<0.001$ ). Prevalence of HIV among pulmonary TB patients was $0.29 \%$ and among extrapulmonary TB patients was $0.48 \%$ ( $p$ value $=0.09$ ).

Conclusion: In public DOTS clinics in Pakistan it is feasible to test TB patients for HIV. Prevalence of HIV is three times higher among TB patients as compared with the general population in Pakistan. Although the results are not representative of Pakistan or Sindh province they cover a large catchment area and closely match WHO estimate for the country. Routinely screening all TB patients for HIV infection, especially targeting men and ensuring antiretroviral therapy, can significantly improve TB/HIV collaborative activities in Pakistan and identify many cases of HIV, improve health outcomes and save lives.

\section{INTRODUCTION}

In recent years Pakistan has moved from having low-HIV prevalence to a concentratedHIV epidemic. ${ }^{1}$ Prevalence of HIV among the

\section{ARTICLE SUMMARY}

Article focus

- To investigate the feasibility of HIV screening among tuberculosis (TB) patients registered for treatment at selected TB centres in Sindh province of Pakistan.

- To describe the prevalence of HIV among TB patients in the study area.

Key messages

- The study demonstrates the feasibility of acceptance of screening large number of TB patients for HIV.

- Prevalence of HIV among TB population is threefold higher as compared with general population.

- Overwhelming majority of HIV-infected TB patients detected were men.

Strengths and limitations of this study

- The study covers a large catchment area and the results closely match WHO estimate for the country.

- Since the study was confined to six public facilities in Sindh, the results are not representative of Pakistan.

general population in Pakistan is still low $(0.1 \%)$ and the estimated number of cases in the country of 180 million people is under 100000 , of which only about 7000 cases are reported. ${ }^{1}$ HIV cases detection and treatment is one of the important HIV prevention strategies. Finding HIV cases among tuberculosis (TB) patients and providing antiretroviral therapy (ART) will contribute significantly not only in HIV/AIDS prevention but also improve outcomes of TB treatment in HIV positive TB patients. ${ }^{2}$

Pakistan ranks fifth among the countries with highest burden of $\mathrm{TB}$ in the world and contributes to about $63 \%$ of TB burden in the Eastern Mediterranean Region. ${ }^{3}$ Estimated prevalence and incidence of TB (all forms) in Pakistan is 310/100 000 and 231/100 000, respectively. ${ }^{3}$ 
TB is the leading cause of death among HIV patients. ${ }^{2}$ The unfavourable synergy between HIV and TB epidemics has added significantly to the suffering and death caused by each disease alone. ${ }^{4}$

In 2004 WHO released guidelines for HIV surveillance among TB patients recommending that generalised and concentrated epidemics use data from routine HIV counselling and testing of all TB patients form the basis for the surveillance. ${ }^{5}$ Pakistan had a low-level epidemic and integration of these TB/HIV services was not prioritised. Updated guidelines recommend that all TB patients be screened for HIV and emphasised the need to establish mechanisms for delivering integrated TB and HIV services, preferably at the same time and location. ${ }^{5}$ Furthermore, surveillance provides information necessary to monitor the effectiveness of joint strategies aimed at reducing the impact of HIV among TB patients. However, in 2010 Pakistan reported that only $2 \%$ of TB patients knew their HIV status and that nationally, only $22 \mathrm{~TB} / \mathrm{HIV}$ patients were reported and only 9 put on ART. ${ }^{3}$

The objectives of this study were to investigate the feasibility of HIV screening among TB patients registered for treatment in selected TB treatment centres in Sindh province and to describe the prevalence of HIV among TB patients in the study area.

The specific aims of the study were to educate and counsel TB patients about HIV/AIDS, to implement TB/HIV registration at DOTS centres, to register HIV-infected TB patients at ART centres for treatment and to determine the refusal rate for HIV screening among TB patients.

\section{METHODS}

We conducted a cross-sectional study of TB patients (all forms) registered in selected six sentinel sites (TB treatment centres) under the National TB Control Program (NTP) in the Sindh province of Pakistan from April 2008 to March 2012. Most TB patients in Pakistan are treated at public DOTS. Three of these centres are located in Karachi and the remaining centres are situated in the central and northern districts of Sindh province. Each selected centre has a catchment area covering more than 300000 residents. These sites were selected on the basis of adequate number of TB cases registered annually, trained staff and a separate room for the education and counselling of $\mathrm{TB}$ patients to ensure privacy and confidentiality. All TB patients, diagnosed following NTP guidelines, aged 16-60 years who gave informed consent were included in the study. These patients were provided education and counselling for HIV by trained social mobilisers ensuring confidentiality and privacy and their demographic information was recorded in TB/HIV register, maintained at each site. Social mobilisers are trained persons who provided education and counselling to $\mathrm{TB}$ patients and performed rapid HIV tests and maintained $\mathrm{TB} / \mathrm{HIV}$ register.
Demographic information collected included age, gender, area of residence (urban or rural) and type of TB (pulmonary or extrapulmonary). Data were collected interviews and recorded on the standard TB/HIV registers maintained at each site. The data were then abstracted from these registers for the study. Patients were tested for HIV using Rapid HIV kit (Bioline HIV-1/2 3.0, Standard Diagnostic Inc, Kyonngi-do, Korea). Those whose rapid test results were non-reactive were given results after post-test counselling. Venous blood samples were taken from people whose rapid test results were reactive and sent to the Referral Lab of Sindh AIDS Control Program for confirmation using the UNAIDS/Government of Pakistan HIV testing strategy based on three different test principles or test antigens. At the referral laboratory samples were initially cross checked on HIV1\&11 Determine Rapid kit and all reactive samples were further tested using two different ELISA (HIV Ag/Ab Combination by Abbott Murex and HIV Ansi-labsystem kits using Multiscan MS ELISA Reader). All confirmed HIV-positive TB patients were provided results linked with reference codes and with post-test counselling and then referred to HIV treatment at Civil Hospital Karachi for further care and support services including ART according to national guidelines.

\section{Statistical analysis}

Data were entered twice by separate operators using Epi Data V.3.1 (The EpiData Association, Odense, Denmark). Data were cleaned and analysis was performed using Statistical Package for Social Sciences (SPSS) V.16.0 (IBM Corporation). For continuous variables summary statistics were computed. Frequencies were calculated for categorical variables. $\chi^{2}$ and Fisher Exact tests (where required) were used to compare different variables between HIV-positive and HIV-negative TB patients. Bivariate analysis was performed for estimation of OR and $95 \%$ CI. A p value of $<0.05$ was considered significant.

\section{ETHICAL REQUIREIMENT}

The study was approved by the Ethical Review Committee of Bridge Consultants Foundation, which is registered with the Office of Research Protection, National Institute of Health, USA.

\section{RESULTS}

A total of $18461 \mathrm{~TB}$ patients were registered for treatment at the six sentinel sites during the study period. Of the total TB patients, 12822 met the study criteria for age and received counselling. In total, 270 did not wish to be included in the study and $97.8 \%(\mathrm{n}=12$ 552) accepted HIV testing. The mean age was 32 years (range 16-60 years) and $47.8 \%(n=6011)$ of these tested patients were men. Of the total screened $76.9 \% \quad(\mathrm{n}=9655)$ had pulmonary $\mathrm{TB}$ and $22.9 \%(\mathrm{n}=2867)$ were extrapulmonary TB patients. A total of 42 people were found to be HIV positive for a 
Table 1 Characteristics of TB patients screened for HIV in Sindh, Pakistan

\begin{tabular}{llll}
\hline Characteristic & $\mathbf{N}$ & $\mathbf{n}$ & Per cent \\
\hline Sex & 12552 & & \\
$\quad$ Male & & 6011 & 47.88 \\
$\quad$ Female & & 6541 & 52.11 \\
Age & 12552 & & \\
$\quad<18$ & & 2359 & 18.8 \\
$\quad$ 18-44 & & 7241 & 57.7 \\
$\quad>44$ & 12552 & 2952 & 23.5 \\
TB diagnosis & & 9655 & 76.9 \\
$\quad$ Pulmonary & & 2867 & 22.8 \\
$\quad$ Extrapulmonary & & 42 & 0.33 \\
HIV positive & 12552 & & \\
\hline TB, tuberculosis. & & & \\
\end{tabular}

prevalence of $0.34 \%$ (table 1). Prevalence of HIV among men was $0.67 \%$ and $0.03 \%$ among women ( $p$ value $<0.001)$. Prevalence of HIV among extrapulmonary TB cases was $0.48 \%$ whereas prevalence of HIV among pulmonary cases was $0.29 \%$. Prevalence of HIV in TB patients between 18 and 44 years old was $0.50 \%$ while prevalence of among those older than 44 years of age was $0.17 \%$ (table 2). All 42 patients whose confirmatory tests results were returned positive returned for their results. Of the 42 HIV-positive patients found, 35 were successfully registered at the ART site.

\section{DISCUSSION}

The study demonstrates the feasibility and acceptance of screening large number of TB patients for HIV and linking them to antiretroviral treatment. Our study found a threefold-higher prevalence of HIV among TB patients compared with the general population, and the overwhelming majority of the HIV-infected TB patients detected were men.

Table 2 Associations of HIV screening results among TB patients Sindh, Pakistan 2008-2012

\begin{tabular}{|c|c|c|c|c|}
\hline \multirow[b]{2}{*}{ Variable } & \multicolumn{2}{|c|}{ HIV positive } & \multirow[b]{2}{*}{ OR (95\% Cl) } & \multirow[b]{2}{*}{ p Value } \\
\hline & $\bar{n}$ & Per cent & & \\
\hline \multicolumn{5}{|l|}{ Sex } \\
\hline Male & 40 & 0.67 & $\begin{array}{l}21.35 \\
\text { (5.15 to } 88.52)\end{array}$ & $<0.0001$ \\
\hline Female & 2 & 0.03 & 1 & \\
\hline \multicolumn{5}{|l|}{ Age (years) } \\
\hline$<18$ & 1 & 0.04 & 1 & \\
\hline $18-44$ & 36 & 0.50 & $\begin{array}{l}0.21 \\
(0.02 \text { to } 1.73)\end{array}$ & 0.15 \\
\hline$>44$ & 5 & 0.17 & $\begin{array}{l}2.32 \\
(0.97 \text { to } 5.56)\end{array}$ & 0.06 \\
\hline \multicolumn{5}{|l|}{ TB classification } \\
\hline Pulmonary & 28 & 0.29 & 1 & \\
\hline Extrapulmonary & 14 & 0.48 & $\begin{array}{l}0.55 \\
(0.29 \text { to } 1.06)\end{array}$ & 0.09 \\
\hline
\end{tabular}

The prevalence of HIV among TB patients was found to be $0.34 \%$ and while this figure is considerably less than $12 \%$, WHO's estimate of HIV among the world TB patients is in line with the estimates for Pakistan $(0.3 \%) .^{3}$

In Pakistan the male-to-female ratio in the reported HIV cases is $10: 1 .^{6}$ This gender difference was also evident in HIV positive TB patients in our study. The prevalence of HIV was 22 times higher among male TB patients $(0.67 \%)$ compared with female TB patients $(0.03 \%)$. Sexual promiscuity has been reported as less common among female population as compared with male population in Pakistan. ${ }^{7} 8$ Moreover a significant number of reported HIV/AIDS cases in Pakistan have been male overseas Pakistani workers, deported from Gulf countries. ${ }^{9}$ Because of extramarital sexual activities of these male workers they are at greater risk of HIV infection. ${ }^{10}$ Furthermore the current HIV epidemic in Pakistan is partially driven by injection drug users (IDUs), and the vast majority of IDUs in Pakistan are men. ${ }^{11}$ Prevalence of HIV among IDUs in Karachi in Pakistan is up to $42.2 \% .^{12}$

Prevalence of HIV infection was 1.65 times higher among extrapulmonary TB cases as compared with pulmonary TB cases in our study (prevalence $0.48 \%$ vs $0.29 \% \mathrm{p}$ value 0.09 ). Although the difference is insignifcant this could be due to small number of HIV cases detected in our study. This result compares favourably with a similar study done in India in which it was found that HIV infection is 1.3 times more likely among the extrapulmonary patients. ${ }^{4}$ Similar results have been observed in studies done in developed countries. ${ }^{13}$

Refusal rate for HIV testing in our study was $<3 \%$. Since TB patients received education about HIV/AIDS by trained community mobilisers and were counselled for HIV testing, this resulted in low refusal rate in our study. In similar study done in India a refusal rate of $7.8 \%$ was observed. ${ }^{4}$ Screening of 12552 TB patients in six sentinel sites with low-refusal rate suggests that screening of TB patients in DOTS treatment centres is feasible and the concerns about high refusal rate are not legitimate.

This study has a couple of important limitations. The study area was confined to six public facilities in Sindh. While all TB patients between 16 and 60 were approached for inclusion in the study the results cannot be assumed to be representative of Pakistan or even Sindh province. However, our results cover a fairly large catchment area and closely mirror the WHO estimates for the country. We were also not able to test $\mathrm{TB}$ patients that receive care in the private sector. ${ }^{14}$ We were unable to get confirmed data on the smear status of the TB patients. This limits the ability to better disaggregate the data analysis and should be considered in future associations.

In Pakistan the number of patients diagnosed each year with TB is about 400000 . If all of these cases were screened for HIV, about 1200 more cases of HIV could be detected each year. In Sindh, there are around $70000 \mathrm{~TB}$ cases reported each year and the potential 
for HIV case detection scalable screening are still quite large. As a result of this study 35 patients were put on ART. Our results demonstrate the feasibility of implementing WHO TB/HIV guidelines in Pakistan. By scaling up the screening and linking detected HIV cases to ART centres, the spread of HIV may be better controlled in Pakistan and outcome of TB treatment can be improved and many lives can be saved. ${ }^{15}$

Acknowledgements The authors would like to thank Ghulam Sarwar and Javaid Hussain for their assistance in field work and data entry.

Contributors JH, SAS and GNM designed the study; JH and AAC conducted the data collection; AM performed the laboratory analysis; all six authors participated in statistical analysis and data interpretation; JH, JC and SAS wrote the manuscript. All six authors approved the final manuscript.

Funding Funded by Global Fund to Fight AIDS, Tuberculosis and Malaria. Competing interests None.

Ethics approval Ethical Review Committee of Bridge Consultants Foundation. Provenance and peer review Not commissioned; externally peer reviewed. Data sharing statement Extra data are available from the corresponding author.

\section{REFERENCES}

1. UNIADS. UNGASS Country Progress Report: Pakistan. National AIDS Control Program Pakistan (2012). http://www.aidsdatahub.org/ dmdocuments/UNGASS_2012_Pakistan_Narrative_Report.pdf (accessed Aug 2012)

2. UNAIDS. UNAIDS World AIDS Day Report 2011. Geneva: UNAIDS, 2011. www.unaids.org/en/media/unaids/contentassets/documents/
unaidspublication/2011/JC2216 WorldAIDSday report 2011 en.pdf. (accessed Feb 2012).

3. WORLD Health Organization. Global tuberculosis control 2011. Geneva: WHO, 2011. www.who.int/tb/publications/global_report/en/ index.html. (accessed Feb 2012).

4. Raizada $\mathrm{n}$, Chauhan LS, Khera A, et al. HIV seroprevalence among Tuberculosis patients in India, 2006-2007. PLoS One 2008;3:e2970. doi:10.1371/journal.pone.0002970.

5. World Health Organization. Guidelines for HIV surveillance among TB patients. 2nd edn. Geneva: WHO, 2004:11-3.

6. Siddiqui AR, Qian HZ, Altaf A, et al. Condom use during commercial sex among clients of Hijra sex workers in Karachi, Pakistan (cross-sectional study). BMJ Open 2011;1:e000154.doi: 10.1136/ bmjopen-2011-000154.

7. Li N, Boulay M. Individual, familial and extra-familial factors associated with premarital sex among Bangladeshi male adolescents. Sex Health 2010;7:471-7.

8. Bradby H, Williams R. Behaviours and expectations in relation to sexual intercourse among 18-20 years old Asians and non-Asians. Sex Transm Inf 1999;75:162-7.

9. Shah SA, Khan OA, Kristensen S, et al. HIV-infected workers deported from the Gulf States: impact on Southern Pakistan. Int $J$ STD AIDS 1999;10:812-14.

10. Faisel A, Cleland J. Migrant men: a priority for HIV control in Pakistan. Sex Transm Infect 2006;82:307-10.

11. Agha A, Parviz S, Younus M, et al. Socio-economic and demographic factors associated with injecting drug use among drug users in Karachi, Pakistan. J Pak Med Assoc 2003;53:511-16.

12. Pakistan National AIDS Control Program. HIV Second Generation Surveillance in Pakistan. National Report Round IV 2011. Islamabad: National AIDS Control Program Pakistan, 2011:32-87.

13. Yang $Z$, Kong $Y$, Wilson $F$, et al. Identification of risk factors for extrapulmonary tuberculosis. CID 2004;38:199-205.

14. Khan AJ, Khowaja S, Khan F, et al.. Engaging the private sector to increase tuberculosis case detection: an impact evaluation study. Lancet Infect Dis 2012;12:608-16.

15. Cohen MS, Chen YQ, McCauley M, et al. Prevention of HIV-1 infection with early antiretroviral therapy. N Engl J Med 2011;365:493-505. 